\title{
Analisis Komunikasi Organisasi pada Tempat Pelatihan Bulu Tangkis Candra Wijaya International Badminton Centre (CWIBC)
}

\author{
Vincent, Eko Harry Susanto, Muhammad Adi Pribadi \\ vincent.vincent16@gmail.com
}

Fakultas Ilmu Komunikasi Universitas Tarumanagara

\begin{abstract}
One way to interact with other individuals is communication. Every situation in life is influenced by communication. Organizational communication is an important aspect in the organization to achieve common goals in the organization. With organizational communication can prevent conflicts between members of the organization. The purpose of this study was to discuss the analysis of organizational communication at a badminton training place at Candra Wijaya International Badminton Center (CWIBC). This study uses a qualitative approach methodology that is descriptive and with phenomenological research methods. The method of data collection in this study is the method of interviews, nonparticipant observation, library studies and online data. The results of this study are that the same organizational culture applied by organizational members prevents conflicts.
\end{abstract}

Keywords: Communication, Organizational Communication, Organizational Cultural, Badmindton

\begin{abstract}
Abstrak
Salah satu cara untuk berinteraksi dengan individu lain adalah komunikasi. Setiap situasi dalam kehidupan dipengaruhi oleh komunikasi. Komunikasi organisasi menjadi aspek penting dalam organisasi untuk mencapai tujuan bersama dalam organisasi. Dengan komunikasi organisasi dapat mencegah terjadinya pertentangan di antara anggota organisasi. Penelitian ini membahas tentang analisis komunikasi organisasi. Tujuan dari penelitian ini adalah untuk mengetahui bentuk aliran informasi dan budaya organisasi yang terdapat di dalam organisasi. Penelitian ini menggunakan metodologi pendekatan kualitatif yang bersifat deskriptif dan dengan metode penelitian fenomenologi. Metode pengumpulan data yang digunakan dalam penelitian ini adalah wawancara dengan narasumber, observasi non partisipan, studi pustaka dan data online. Hasil dari penelitian ini adalah budaya organisasi yang sama diterapkan oleh anggota organisasi mencegah munculnya pertentangan.
\end{abstract}

Kata Kunci: Komunikasi, Komunikasi Organisasi, Budaya Organisasi, Bulu Tangkis

\section{Pendahuluan}

Manusia sebagai makhluk sosial, pada hakikatnya dalam kehidupan membutuhkan individu atau manusia lain untuk bertahan hidup. Salah satu cara untuk melakukan interaksi dengan orang lain adalah dengan komunikasi. Komunikasi memiliki peran yang penting dan berhubungan dengan keseharian kehidupan manusia, sehingga terkadang kita melupakan bagaimana penyebaran, kepelikan, dan kepentingannya. Setiap situasi kehidupan manusia dipengaruhi oleh bagaimana cara kita berinteraksi dengan orang lain, seperti pesan yang diberikan individu lain, orang-orang dari dekat maupun yang jauh, hidup dan mati (Littlejohn dan Foss, 2009). 
Menurut West dan Turner (2011), komunikasi merupakan proses interaksi sosial di mana individu menggunakan sebuah untuk membuat dan memberikan kesan terhadap makna di dalam lingkungan mereka. Selain dengan keluarga, pada kehidupan sosial komunikasi juga dibutuhkan untuk membangun dan memperbanyak relasi. Termasuk dalam suatu kelompok atau organisasi, komunikasi dibutuhkan oleh dua individu atau lebih agar dapat bekerjasama untuk mencapai suatu tujuan yang sama.

Organisasi merupakan sebuah susunan interaksi yang kompleks, terkadang bertentangan, identitas, yang dimana komunikasi organisasi harus dapat mengatasi situasi majemuk ini. Jadi organisasi harus memiliki cara untuk membuat individu ke dalam identifikasi umum dengan organisasi. Perbedaan identitas, atau bahkan pertentangan, dapat ditangani jika ada keseluruhan identifikasi dengan organisasi sebagai sebuah kesatuan dan pemersatu dalam sebuah organisasi dapat berupa budayanya (Littlejohn dan Foss, 2009).

Komunikasi organisasi yang terjadi di dalam sebuah organisasi dapat membentuk sebuah budaya organisasi nyata yang dibuat secara komunikatif melalui perilaku-perilaku atau praktik-praktik dalam suatu organisasi, yang di dalamnya tidak mengarah pada keanekaragaman etnis, latar belakang, dan ras dari setiap individu. Melainkan, menurut Pacanowsky dan O'Donnell Trujillo budaya adalah cara hidup di dalam sebuah organisasi yang termasuk semua simbol yang disepakati bersama (seperti tindakan, rutinitas, dialog, dan seterusnya) dan pemakanaan yang terdapat pada simbol-simbol. Pemahaman dan pemaknaan bisa dibentuk lewat interaksi yang terjadi di antara karyawan dan pihak atasan (West dan Turner 2011). Setiap organisasi terdapat budaya organisasi yang bermacam-macam dan berbeda dengan organisasi lainnya. Anggota-anggota organisasi juga perlu memahami budaya yang dalam organisasinya agar dapat membuat setiap anggota organisasi mengenali dan memaknai simbol-simbol yang sama di dalam kehidupan organisasi.

Terdapat rumusan masalah yang ada di dalam penelitian ini adalah bagaimana budaya organisasi yang terbentuk di tempat pelatihan bulu tangkis Candra Wijaya International Badminton Centre (CWIBC) yang bertujuan untuk mengetahui pola aliran informasi dan budaya organisasi yang terdapat di tempat pelatihan bulu tangkis tersebut.

\section{Metode Penelitian}

Dalam penelitian ini, terdapat metodologi penelitian yang digunakan adalah metodologi kualitatif yang bersifat deskriptif. Penulis melakukan sebuah penelitian yang berkaitan dengan komunikasi organisasi. Metode yang digunakan dalam penelitian ini adalah metode fenomenologi.

Dalam proses penelitian, metode pengumpulan data yang digunakan adalah metode wawancara dengan narasumber atau informan, observasi non partisipan di lokasi penelitian, dan penelusuran data online. Berdasarkan metode pengumpulan data yang digunakan maka terdapat dua macam data yaitu, data primer dan data sekunder. Semua data primer yang didapat berupa hasil dari wawancara dengan key informan dan informan, lalu hasil dari pengamatan langsung yang dilakukan penulis. Data sekunder dapat berupa informasi yang didapatkan dari sumber online, teori, dan kajian pustaka yang digunakan untuk mengolah dan mengalaisis data untuk mendukung dalam penarikan kesimpulan. 


\section{Hasil Temuan dan Diskusi}

Dalam sebuah organisasi, terdapat individu-individu yang membentuk kelompok dan memiliki sebuah kesamaan tujuan yang ingin dicapai bersama. Maka untuk menyampaikan sebuah tujuan dibutuhkannya sebuah komunikasi. Menurut Abdullah Masmuh (2008), komunikasi dibagi menjadi dua jenis yaitu komunikasi satu arah dan komunikasi dua arah. Selain itu terdapat lima pola aliran informasi dalam organisasi yang biasanya ditemui pada kelompok maupun organisasi (Masmuh, 2008) yaitu:

1. Pola aliran lingkaran

Di dalam pola ini tidak terdapat kehadiran seorang pemimpin. Semua anggota mempunyai kesamaan posisi. Para anggota mempunyai kesamaan kewenangan dan kekuatan. Satu anggota dapat berkomunikasi dengan dua orang anggota lainnya.

2. Pola aliran roda

Pola aliran roda mempunyai kehadiran pemimpin yang terdapat di posisi pusat. Orang yang berada di posisi pusat adalah anggota yang dapat mengirim dan menerima pesan dari anggota yang lain. Maka di dalam pola aliran roda jika satu anggota ingin menyampaikan pesan kepada anggota lain harus melalui orang yang berada di posisi pusat.

3. Pola aliran $Y$

Pola aliran ini kurang terpusat jika dibanding pola aliran roda, namun lebih terpusat jika dibanding pola aliran lingkaran. Di sini juga terdapat seorang pemimpin. Anggota yang berada di posisi pusat bisa mendapat dan mengirim pesan dari dua orang anggota lainnya. Sedangkan, tiga orang anggota lainnya hanya dapat melakukan komunikasi dengan satu anggota lain.

4. Pola aliran rantai

Pola aliran rantai mempunyai kemiripan dengan pola aliran lingkaran tetapi anggota yang posisinya berada di paling ujung hanya dapat melakukan komunikasi dengan satu orang. Selain itu terdapat keadaan terpusat di sini. Anggota yang berada di posisi pusat yang memiliki peran lebih daripada yang ada di posisi lainnya.

5. Pola aliran semua saluran

Pola aliran semua saluran atau yang membentuk sebuah bintang mempunyai kemiripan dengan pola aliran lingkaran yang artinya, semua orang mempunyai kekuatan yang setara. Di dalam pola ini setiap orang dapat melakukan komunikasi dengan anggota yang lain dan membuat adanya partisipasi menjadi optimal.

Penulis menemukan bahwa aliran komunikasi organisasi di tempat pelatihan bulu tangkis Candra Wijaya International Badminton Centre (CWIBC) menggunakan jenis komunikasi dua arah, dan pola aliran informasi di tempat pelatihan bulu tangkis Candra Wijaya International Badminton Centre (CWIBC) membentuk sebuah pola rantai. Seperti yang dikatakan oleh salah satu key informan yaitu Candra Wijaya yang memiliki jabatan sebagai direktur atau kepala pelatih yang tugasnya mengatur, mengontrol, membuat program jadwal latihan, dan arahanarahan secara keseluruhan. 
Menurut Nathalie Ivyana yang menjadi atlet di sektor ganda putri Candra Wijaya International Badminton Centre (CWIBC), dalam pelatihan biasanya program sudah dibuat oleh pelatih dan atlet hanya mengikuti program latihan yang sudah dijadwalkan, dan jika ingin latihan yang lain kita harus nambah latihan sendiri di luar jadwal latihan. Lalu disaat latihan kita dikelompokan pasti saling kenal dalam kelompok pelatihan, dan saling sharing atau kasih masukan sesama teman pelatihan.

Gambar 1. Pola Aliran Komunikasi

Candra Wijaya International Badminton Centre (CWIBC)

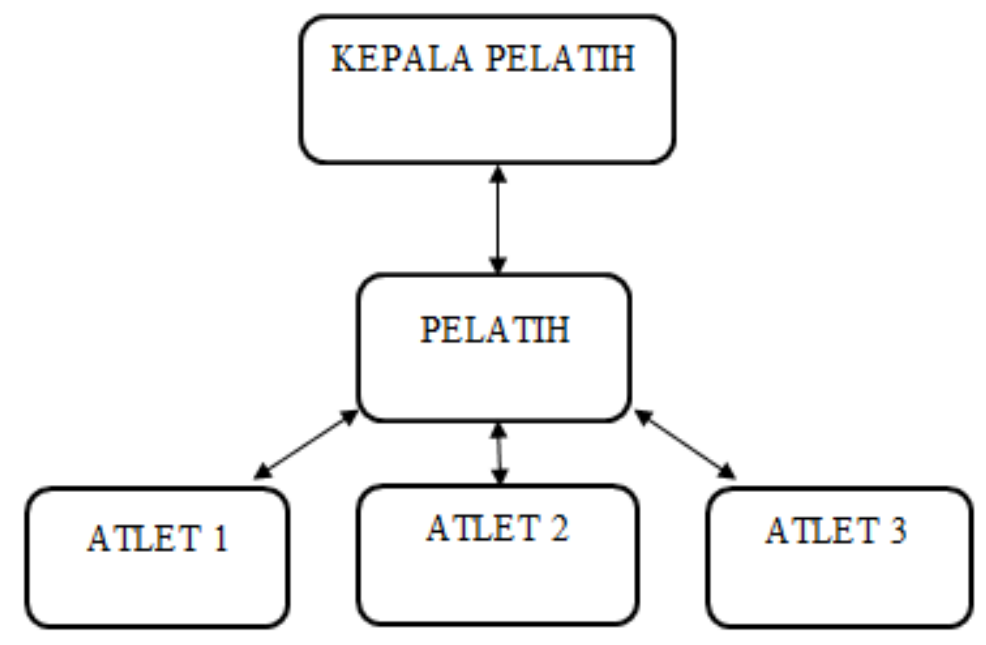

Sumber: Dokumentasi Peneliti (2018)

Menurut Schein, terdapat tiga tingkatan yang dapat ditemukan dalam budaya organisasi (dalam Romli, 2011) yaitu: Artefak, Nilai, dan Asumsi Dasar.

1. Artefak

Pada tingkatan ini sifat budaya dapat terlihat mata tetapi anggota organisasi sering tidak dapat mengartikan, seperti lingkungan fisik organisasi (lokasi, waktu, dan sejarah), cara berpakaian, dan teknologi. Pada tingkat ini analisis cukup rumit karena mudah didapatkan namun sulit didiartikan.

2. Nilai

Pada tingkatan ini, memiliki tingkat kesadaran yang lebih tinggi dari artefak. Nilai tidak mudah diamati secara langsung sehingga untuk meyimpulkan seringkali dibutuhkan wawancara dengan anggota organisasi yang mempunyai posisi kunci (key informan) atau dengan menganalisis kandungan artefak seperti dokumen.

3. Asumsi dasar

Pada tingkatan ini terdapat pembeda di antara asumsi dengan nilai terletak pada apakah nilai-nilai di dalam organisasi masih diperdebatkan dan diterima apa adanya atau tidak. Asumsi dasar dapat digunakan sebagai alat untuk menilai budaya suatu organisasi, karena asumsi dapat memberikan gambaran apa yang dipercayai oleh anggota sebagai kenyataan dan karenanya mempengaruhi apa yang mereka pahami, mereka pikirkan dan rasakan.

Berdasarkan teori di atas, jika dikaitkan dengan hasil dari pengumpulan data yang telah dilakukan maka budaya organisasi yang terdapat di tempat pelatihan bulu 
tangkis Candra Wijaya International Badminton Centre (CWIBC) adalah melepas alas kaki saat menuju ke lapangan, jadwal pelatihan yang rutin, dan budaya organisasi yang dibuat melalui visi dan misi yang telah diterima dan dipahami yaitu, integritas dan militan.

Gambar 2. Ruangan untuk Menaruh Alas Kaki sebelum Menuju ke Lapangan

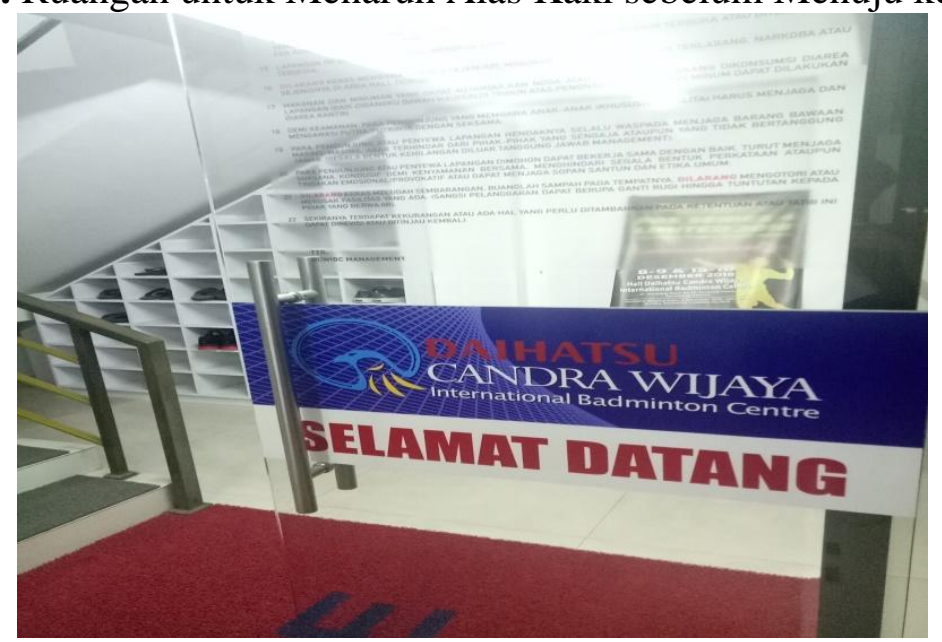

Sumber: Dokumentasi Peneliti (2018)

Gambar 3. Gambaran pada Saat Program Pelatihan

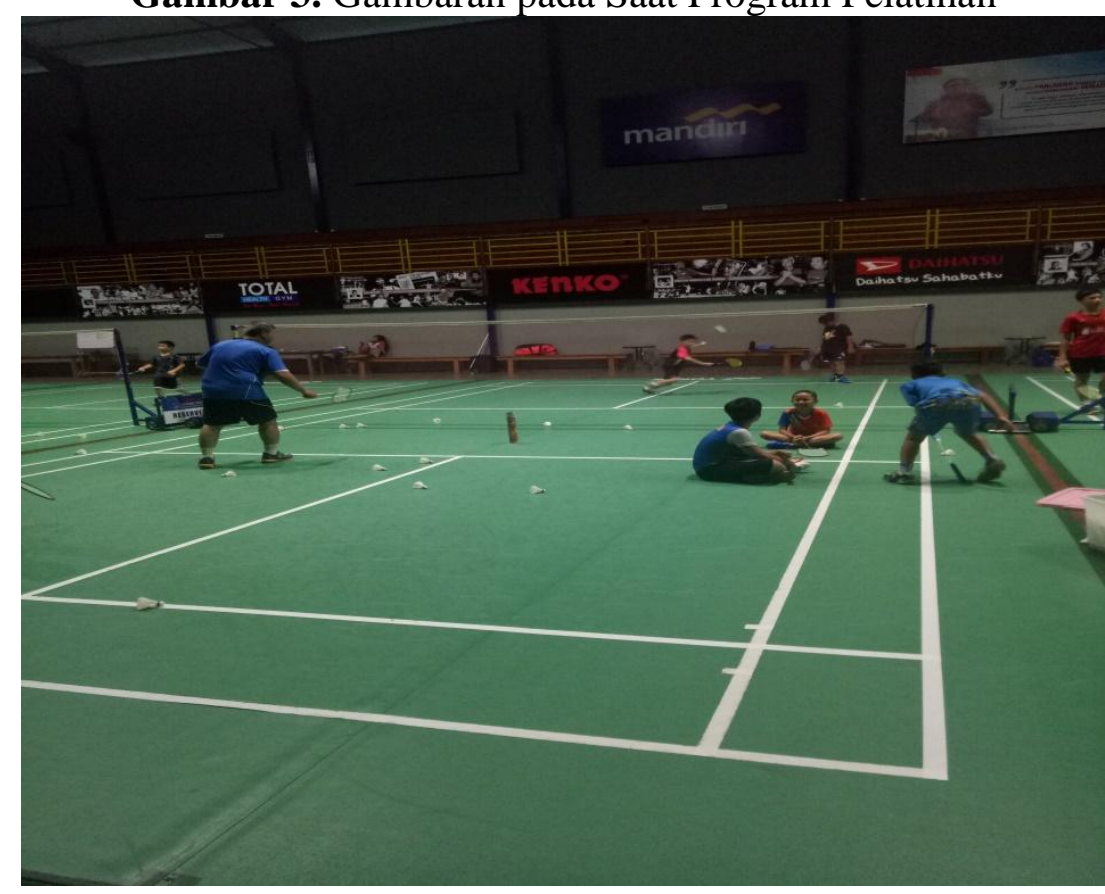

Sumber: Dokumentasi Peneliti (2018)

\section{Simpulan}

Berdasarkan hasil penelitian yang telah dilakukan tentang komunikasi organisasi di tempat pelatihan bulu tangkis Candra Wijaya International Badminton Centre (CWIBC), maka peneliti mengambil kesimpulan sebagai berikut: 1) Jenis komunikasi organisasi yang digunakan di tempat pelatihan bulu tangkis Candra Wijaya International Badminton Centre (CWIBC) menggunakan komunikasi satu 
dua arah, membentuk sebuah aliran informasi komunikasi organisasi yang berbentuk rantai, 2) Tempat pelatihan bulu tangkis Candra Wijaya International Badminton Centre (CWIBC) membentuk budaya organisasi yang sama sejak awal dan diterapkan oleh seluruh anggota organisasi dapat mencegah munculnya pertentangan di dalam organisasi, dan budaya organisasi yang dibentuk adalah melepas alas kaki saat menuju ke lapangan, jadwal pelatihan yang rutin, integritas dan militan.

Saran penulis adalah komunikasi yang terjadi di tempat pelatihan bulu tangkis Candra Wijaya International Badminton Centre (CWIBC) lebih ditingkatkan agar terjadi komunikasi yang lebih interaktif. Dengan pelatih menerima masukan dari para atlet tentang program pelatihan, maka dapat membuat kemampuan para atlet menjadi maksimal. Budaya organisasi yang ada di tempat pelatihan bulu tangkis Candra Wijaya International Badminton Centre (CWIBC) agar dapat dipertahankan karena dengan budaya organisasi yang ada dapat mencegah munculnya pertentangan.

\section{Ucapan Terima Kasih}

Pada kesempatan ini, penulis mengucapkan terima kasih kepada Tuhan Yang Maha Esa, serta kepada pembimbing dan co-pembimbing yang telah membantu dalam menyelesaikan skripsi dan jurnal ini yaitu Bapak Dr. Eko Harry Susanto, M.Si., dan Bapak Dr. Muhammad Adi Pribadi., S.E., MIB., M.Comm., dan kepada seluruh pihak yang turut membantu dan mendukung yang tidak dapat disebutkan satu-persatu.

\section{Daftar Pustaka}

Littlejohn, Stephen W., \& Foss, Karen A. (2009). Teori Komunikasi. Jakarta: Salemba Humanika.

Masmuh, Abdullah. (2008). Komunikasi Organisasi dalam Perspektif Teori dan Praktek. Malang: Universitas Muhammadiyah Malang Press.

Mulyana, Deddy. (2013). Ilmu Komunikasi: Suatu Pengantar. Bandung: Remaja Rosdakarya.

Romli, Khomsahrial. (2014). Komunikasi Organisasi Lengkap. Jakarta: Kompas Gramedia.

West, R., \& Turner, Lynn H. (2011). Pengantar Teori Komunikasi: Analisis dan Aplikasi. Jakarta: Salemba Humanika. 